4.

\title{
Beiträge zur pathologischen Anatomie einer Form der Schädelatrophie.
}

Von Professor Dr. Maier in Freiburg i. B.

Die Besprechung einer interessanten Form der Sclädelatrophie, die Professor Virchow in jüngster Zeit aufführte, bestimmte mich, die zwei in unserer hiesigen Sammlung vorfindlichen Exemplare einer näheren Untersuchung zu unterwerfen. Ich glaube, dass die Veröflentlichung schon als numerischer Beitrag gerechtfertigt ist, noch mehr dadurch, dass das anatomische Bild dieser Schädel mir andere Verhältnisse zeigte, als die von Prof. Virchow untersuchten diesem Forscher darboten. Ueberdiess führt der eine eine praktische Bedeutung mit sich durch eine Verletzung, die er zeigt, welche auch den Tod des betreffenden Individuums mit sich führte.

\$3as eine Präparat ist die Scbädeldecke einer alten Frau, etwas klein, mit mässiger Wölbung. Sämmtliche Nähte sind verwachsen, so dass die Decke wie aus einer knöchernen Schale zu bestelen scheint. Der Knechen zeigt sich ausserordentlich porös; die Farbe ist aussen und innen exquisit gelb. Das Planum semicirculare ist fast senkrecht gestell, so dass bei dem schnellen Abfall von der Linea semicircularis diese Linie wie eine Randleiste beiderseits die mittlere Kuppel des Schädels und die flachen Seitentheile trennt. Links findet sich ein Sprung im Sclädel, der in dem grossen Flügel des Keilbeins in der Schläfengrube beginnt, nach aufwärts eilend, die Linea semicircutaris durchschneidet, durch das Seitenwandbein eine förmliche Diagonale zielt, die Tubera derselben durchsetzt rnd, über die verwachsene Lambda-Naht gehend, etwa in der Mitte des Hinterhauptsbeines endet. Ein zweiter Sprung durchschneidet das Tuber parietale rechts, etwas vor demselhen beginnend, und endet ebenfalls nach unten im $0 s$ occipitis.

Nur einige Stellen sind von der oben berïhrten gelben Färbung ausgenommen, nämlich beiderseits die vordere Partie der Schläfengrube und dann die stellen der Tubera parietalia, vor denen diese verschiedene Färbung noch etwas nach abwärts und gegen die Mitte weiter zieht, so dass sie in der Lambdanaht zusammentrifft. Diese Stellen unterseheiden sich in doppelter Beziehung vom übrigen Schädel, einmal durch ihr weissliches Aussehen und sodann durch ihre papierene Dïnnleit. Diese verdïnnten Stellen sind überall von einem Randwulste umgeben, der dieselbe Dicke der übrigen Schädeldecke besitzt und der, allmälig oder rascher sich verjüngend, schliesslich in diese dünne Lamelle ỉbergeht. Da wo diese dünnen und

*) Verhandlung. d. Würzb. phys. - med. Gesellschaft. Bd. IV. Hft. III. 
weissen Stellen ringsum gegen ilire wallartige Umgebung emporsteigen, verlieri sich auch allmälig ilıre Farblosigkeit, und es stellt sich immer mehr eine exquisit gelbe Färbung ein. Am Schläfenbein lässt sich die Ausdehnung dieser dünnen Stelle schwer bestimmen, da das Präparat nur das abgesägte Schädeldach darstellt, und der Schnitt mitten durch diese Partie hindurch führte. Es erstreckt sich aber diese Atrophie bis gegen die Linea semicircularis, also weit über die Stelle linaus, die normal immer die gefährliche Dünne des Schädels darstellt.

Am Tuber parietale beiderseits zeigt die atrophische Stelle eine ziemlich runde Form in der Grösse eines Zwölflkreuzerstücks. Der Knochen ist an diesen Stellen so verdünnt, dass er vollkommen durchscheint. Er zeigt sich, gegen das Licht gebalten, fein porös. Diese weisse Platte nun entspricht der Lagerung nach der Tabula vitrea, da, von aussen gesehen, der Schädel im ganzen Umfange dieser Stelle in die Tiefe abfällt und sie mit einem Randwulste umgiebt, innen aber diese Purtien in vollkommen einer Ebene mit der inneren Seite der Tabula vifrea liegen. An den Uehergangsstellen von den verdünnten Theilen in den dicken Knochen geht, bei durchscheinendem Lichte besehen, die weisse Farbe nicht plötzlich in die gelbe des übrigen Knochens über, sondern allmälig. Jedoch ist diese gelbe Färbung durchaus keine gleichmässige, vielmehr zeigen sich überall am Schädel an seiner äusseren und inneren Oberläche weissliche Punkte und Linien eingesprengt, die, oft in wurmförmigen Figuren gezogen, dem Schädel eine eigenthümliche Zeichnung verleihen. Gegen das Licht gehalten, zeigen sich an den durchscheinenden Stellen jene weissliclien Partien als undurchsichtig, daher bei dieser Ansicht jene Zeichnung sich noch deutlicher herausstellt. Zugleich erweist sich bei durchfallendem Lichte, wie vom Rande dieser atrophischen Zellen aus jenes reticulirte Ansehen immer mehr gegen die durchscheinenden Stellen sich verliert. Knochenverdickungen oder Auflagerungen sind weder aussen noch auf der Innenfläche des Schädels zu sehen. Da wo die Arteriae meningeae über die verdünnten Stellen ziehen, ist die Knochentafel, die noch als Wand der Sulci dient, dünner als Postpapier. Auf der durchsägten Stelle sowohI, als an der Bruchstelle, zeigt der Knochen nicht die deutliche Zeichnung der von zwei Lamellen eingeschlossenen diploetischen Substanz, sondern einer durchgängigen und gleichförmigen Masse mit nur theilweise möglicher Sonderung einer Lamina externa und inlerna.

Der andere, etwas grössere Schäde gehörte ebenfalls einer alten Frau, Er ist von regelmässiger Wölbung und mässiger Dicke. Auch an ihm ist die starke gelbe Fürbung gleich auf den ersten Blick auffallend und ebenso auch die starke Porosität. Nur erscheint jenes reticulirte Ansehen nicht so deutlich über den ganzen Schädel verbreitet, sondern vorzugsweise nur um die atrophischen Stellen. Auch hier zeigen sich wieder zwei Stellen des Schädels in dieser interessanten Weise verdünnt. Einmal die oben berührte Stelle in der Schläfengrube und dann beiderseits die Tubera parietalia. Die beiden Seitenwandbeine sind an dem bezeichneten Orte in der Ausdehnung von melr als 2 Zoll in der Länge und mehr als 1 Zoll in der Breite zu einer äusserst dünnen Knochenlamelle zusammengeschmolzen, die ebenso, wie am vorigen Schädel, von einem Walle umgeben ist. Die atrophirte Stelle links bietet eine dreiseitige, die rechte eine ovale Figur dar. Archiv f. pathol. Anat. Bd. VII. Heft 2. 


\section{8}

Diese Partien sind auf eine exquisite Weise von Porenkanälchen durchbrochen und ganz siebförmig fest anzusehen. Auch hier sind am Schädel nirgends sonst Auflagerungen oder Sclerosirungen zu sehen. Die übrigen Verhältnisse sind zum Theil irrelevant, zum Theil wie am oben beschriebénen Schädel; ich übergehe sie daher.

Ich habe nun von beiden Schädeln zahlreiche Durchschnitte aus den verschiedensten Stellen genommen, diese einer genauen mikroskopisclen Untersuchung unterworfen, um mir eine Einsicht in den Prozess zu versehaffen.

Wenn man eine von jenen atrophirten Stellen entfernte Partie des Schädels, also eine scheinbar normale, für die mikroskopische Untersuchung präparirt, so fällt dabei schon die grosse Brüchigkeit und Porosität des Knochenstückchens auf. Unter dem Mikroskop nun erweist sich, dass der Knochen wesentlich verändert ist. Es ist nämlich sowohl Lamina externa als interna fast gänzlich geschwunden und an ihre Stelle ein poröses Gewebe getreten, so dass das ganze Knochenstück aus diploetischer Substanz zu besteben scheint. Von einem dünnen knöchernen Balkengefüge gebildet, zeigt sich ein Maschennetz gleichsam, das grössere und kleinere Alveolen umschreibt, die von einer amorphen Masse ausgefüllt sind. Es ist nun bei näherer. Untersucling ganz deutlich, dass man hier erweiterte Haversische Kanälchen vor sich hat, die durch ihre ïbermässige Erweiterung dem Knochen das poröse Anselıen geben. Diese KanäJchen haben sich so erweitert, dass an einzelnen Stellen nur noch ganz dünne Knochenbälkchen sie von einander trennen, an andern Stellen aber diese Scheidewände durchbrochen sind, so dass die Hohlräume ineinanderflossen. Man sieht dann oft noch Fragmente solcher Scheidewände, die früheren Lamellensysteme der Haversischen Kanälchen, in die Lumina dieser Alveolen hereinragen. Die Masse, die diese Räume ausfüllt, erweist sich nach mikrochemischen Untersuchungen vorzugsweise aus Fett und Kalkkrümeln bestehend. Ich habe auch Cholestearinkrystalle in ihr gefunden. Diese Veränderung gibt nun dem Knochenstïckchen und ebenso der ganzen Schädeldecke das so sehr veränderte Aussehen. An dem Knochenschliff sieht man statt der äusseren und inneren Tafel und der Diplöe, statt des regelmässigen Lamellensystems um dic Haversischen Kanälchen, ein unregelmässiges, oft unterbrochenes Balkennetz von Knochen, das weite Hohlräume umschliesst. Diese Hohlräume geben durch die äussere und innere Tafel bis an die oberfläche durch und münden dort oft frei, von keinem Knochenbällkchen mehr umschlozsen, so dass die in ihnen enthaltene Masse blossliegt. Diess giebt nun auch dem ganzen Knoclien jenes oben berührte Ansehen der reticulirten Zeichnung, indem über die ganze äussere und innere Oberfläche bald compacte hnochensubstanz (durchsichtig), bald jene Hohlräume mit ilhrem Inhalte bloss liegen. Von Fett ist der ganze Knochen gelb durchtränkt, und jene weisslichen Figuren sind jene zu Tage liegenden Inhaltsmassen der Hohlräume. Gehen wir nun zu den atrophischen Stellen über, so zeigt sich hier auf Durchschnitten ganz dasselbe Bild. Am dicken Rande ist noch in grösserem Verhältniss diese Porosität mit ilıren weiten Hohlräumen sichtbar, mit verkümmerter Lamina externa und interna. Je dünner nun die Stelle wird, desto mehr verliert sich das Bild eines Durchschnittes der Schädelwand, und endlich 
st die dünnste Stelle nur noch von einer Knocbenlamelle gebildet, die viele Porositäten zeigt. Es ist mikroskopisch schwer zu sagen, dass die Lamina externa aufhöre, oder dass die Diplöe verschwunden sei, und nur die Glastafel noch diese Lamelle bilde, da keiner dieser Theile mebr in normalem Bau existirt. Es ist gleichsam Alles eine diploetische Substanz geworden, zu der diese 3 Partien sich veränderten. Der Knochen ist so in seiner Totalität zusammengesintert. Da aber der Prozess, von aussen nach innen gehend, die äusseren Partien zuerst und stärker und schneiler der Schmelzung unterwarf und so von aussen als Depression zu sehen ist, so muss diese diploetische Masse, die noch in gleichem Niveau mit der Glastafel steht, natürlich für diese anch erklärt werden. Einlagerung frischer Knochensubstanz, neve Lamellenschichten in die Diplöe, habe ich nirgends bemerken können.

Es ist also das eine Schmelzung des hnochens, ausgehend von den Haversischen Kanälchen, eine wahre Osteoporosis des Scliädels. Da man sonst nirgends am Schädel Spuren entzündlicher Affection walrnimmt, so ist dieser Prozess als die pathologische Seite des Vorgangs zu nehmen, der sich physiologisch am Knochen bei seinem Wachsthum zeigt, wo aus compacter Knochensubstanż sich die Markröhre bildet, und, auf diesem Punlite angelangt, stimme ich mit Virchow's interessanter Deutung uberein, es ist ein Involutionsprozess, an diesen Schädeln unter dem Bilde einer Osteoporosis senilis. Es ist natürlich schwer, einen Prozess zu bestimmen von einem einzelnen Körpertheil aus, ohne genaue Kenntniss der vorangegangenen Krankheit, und zudem noch an einem getrockneten Knochenpräparate, zu dessen richtiger Deutung auch noch die Kenntniss der Beschafienheit der Beinhant gehört.

Doch lässt sich zur Ausschliessung eines anderen Krankheitsvorganges, nämlich der Möglichkeit der eingetretenen Atrophie durch Druck, behinderte Circulation und Ausdehnung der Gefässe, das wesentlich andere Verhalten der Schädeldecken entgegenhalten, die an der Stelle der Atrophie eine dieselbe ringsumgebende Sclerosis des Knochens zeigen.

Es bliebe nun noch übrig, für die Wahl der Orte, die diese Krankheit zeigt, einige anatomische Anhaltspunkte beizubringen. Die Stelle (Tubera parietalia), wo diese Atrophie besonders häufig vorkommt, erhielt durch die Deutung ihrer Veränderung als eines Involutionsprozesses ihre vollkommen befriedigende Erklärung. Aber auch anatomisch lässt sich hier die frihere Schmelzung gegenüber den übrigen Stellen des Schädels erklären. Es bilden nämlich um die Tubera parietalia herum (wie das die sehr schönen, sowohl ausgemeisselten, als injicirten Knochenpräparate zeigen, die unsere Sammlung Horn Professor Kobelt verdankt) die Cefässe des Knochens grössere und stärkere Anhänfung als sonst wo, sowohl in der Lamina externa als auch in der Diplöe. Die Glastafel zeigt zahlreiche, aber grössere Communicationskanäle, die nicht alle mehr zu den Haversisehen Kanälchen zu rechnen sind. Wenn nun die Sclimelzung des Knochens von den Gefässcianälchen ausgeht, so wird natürlich der Theil desselben, z. B. Os parietare und sein Tuber, der die meisten trägt, auch am schnellsten zusammensinken, und desshalb zeigt sich um die Tubera parietalia herum diese deprimirte Stelle in 
dem sonst durchweg osteoporotisch gewordenen Schädel. Das ist auch der Grund, warum die Schmelzung schnell von aussen nach innen dringt, und warum dic Glastafel länger widersteht. Hie und da zeigt sich auch der Bau des Sclädels am Tuber parietale in der Mitte oder an einer Stelle zur Seite dieser von etwas inehr compacter, wie sclerosirter Natur, mitten in dem von Gefässkanalen durchzogenen Gewebe wie eine Insel liegend, so dass die ungleiche Ausdehnung der atrophischen Stelle, die verschiedene Figurenzeichnung, bald als Dreieck, bald rund oder oval, daher zu entnehmen ist. Dahin gehört anch einer der von Sandifort veröffentlichten zwei Fälle atrophischer Schädel auf der Höhe der Scheitclbeine, von welchem zweiten er sagt: „In dextro latere superficies ossis, medio in sinu, aliquomodo assurgit, sic ut media haecce pars a margine, tolum sinum a reliquo osse separante, distinguatur per foveam, quae parten illam undique ambit."

Bezüglich nun der practischen Bedeutung solcher Affectionen, so ergiebt sich aus dem von mir veröffentlichten Fall, dass solche Schädel vorzüglich gern zut Fissuren neigen, indem die betreffende Person durch einen einfachen Fall auf den Boden jene beschriebene weitgreifende Fissur am Schädel mit erfolgendem Tod erhielt, was forensisch nicht ohne Interesse.

Auch Sandifort berichtet dariber folgendes interessante Factum:

„Huic (Platner, ein Arzt, den er kurz zovor citirt hatte) quippe accidit, ut ad hominem evocaretur, qui, ex tertia aedium contignatione delapsus, ab initio sine sensu quasi dormiens erat. Quia conjectura erat, caput offensum esse, Chirurgus, capillos deradens, monstravit profundiorem et majoris ambitus sinum et depressam calvariam. Dum miratur platnerus, cutim super eam collisam vexatamque non esse, homo expergefactus et incisuram metuens dixi, nihil ibi subesse alieni, sibi a teneris hunc sinum fuisse."

*) Ed. Sandifort. Exercitationes academicae. 1783. S. 77.

**) Sandifort, l. c. S. 75 . 